can arise. It is akin to expecting an orchestra to make good music without a conductor-clearly an impossibility.

There seems to me to have been a conspicuous lack of debate in the British psychiatric press about management issues. Surely there is room for experimentation and research into the efficacy of different approaches.

Perhaps Dr Walk's letter will initiate a productive exchange of views in your columns.

Netherne Hospital

I. F. MACILWAIN

Coulsdon, Surrey

\section{Is the College hidting behind a smokescreen?}

DeAr SIR

The Presidents of eight of the medical Royal Colleges were among ten eminent medical men who signed a letter to the Minister of Sport about the sponsorship of sport by tobacco companies (BMJ, 6 February 1982). Unhappily, the President of the Royal College of Psychiatrists was not one of the eight. It is hard to believe that the President would not have supported his fellow Presidents if requested, so we are forced to conclude that he was overlooked. If this is true then the College have only themselves to blame.

Psychiatrists as a profession have had little to say on the subject of smoking, despite the internationally famous research being carried out at the Addiction Research Unit of the Institute of Psychiatry. In psychiatric hospitals patients are positively encouraged to smoke on the vast majority of wards. Psychiatrists could be accused of callously ignoring their patients' physical health in this regard, as well as taking no account of those non-smoking in-patients who are forced to stay in a polluted atmosphere.

At least 50,000 premature deaths and 50 million days off work a year can be related to cigarette smoking. It is high time that our College took a more active role in combating this major health problem.

\section{St George's Hospital}

London SWI7

II was approached and I did in fact sign the letter to the Minister of Sport referred to in Dr Cobb's letter. For reasons I do not understand my name was not among the signatories when the letter was published-K. RAWNSLEY.I

\section{Personal psychotherapy in a psychiatrist's training}

Dear Sir,

Perhaps the irony of it all prompted this, my first letter to your Bulletin. I had just enrolled for the M.Phil. degree at the
Institute of Psychiatry, finished a demanding day at the Camberwell Child Guidance Unit, climbed off the Couch, returned home to read the Membership Examination results (passed) in your Bulletin, and turned a few pages to see Professor Marks's warnings of the dangers in intensive personal psychotherapy with its 'serious drawbacks for training' (Bulletin, March 1982, 6, 39). If ever a claim rests on 'doctrine rather than evidence', this may be the one.

Unless my personal experience is statistically insignificant, may I try to validate my claim. Quite contrary to my personal psychotherapy being a serious drawback in my training, I find it an essential contribution to my aspirations of practising clinical psychiatry at a high standard. Furthermore, in many ways it has contributed to ideas that I hope will fulfil the requirements of the M.Phil. degree. Thus it has stimulated growth rather than fostered inhibitions during training'. Finally, I have not become hostile to alternative approaches of therapy, but continue to respect the competent practitioners of behavioural, family and group approaches and retain the awareness of the efficacy of psychoactive drugs when wisely used.

I am aware of the dangers in generalizing from the individual to the group, but equally there is the phenomenon of individual differences within groups. While personal psychotherapy may not be essential in the training of all psychiatrists, some individuals within the group called 'training psychiatrists' may derive great benefits from the experience, contributing to professional as well as selfgrowth .... and tolerance!

George halasz

Maudsley Hospital

London SES

\section{DeAR SIR,}

I read with interest the various points of view offered on the role of personal psychotherapy in the training of a psychiatrist (Bulletin, March 1982, 6, 38-42).

As a trainee who has not undergone personal psychotherapy, I find Dr Steiner's reference to 'projective identification', and the consequent potential damage to both the untrained therapist and the patient, quite dramatic.

While an undergraduate, I was impressed by the statistics which showed that psychiatrists had a high risk for suicide. If Dr Steiner could show that psychiatrists who have had personal psychotherapy commit suicide significantly less than their more eclectic colleagues, then his point would be well made.

3 Glenville Drive

Michael Hugh O’Rourke 